\title{
Compreendendo a História de Vida de idosos institucionalizados*
}

\author{
Understanding theHstory of Life of institutionalized edderly
}

Maria José Sanches Marin ${ }^{1}$
Fabiana Accioli Miranda ${ }^{2}$
Daniele Fabbri ${ }^{2}$
Laura Privatto Tinelli ${ }^{2}$
LuanaVergian Storniolo ${ }^{2}$

Resumo

Considerando que a institucionalização muitas vezes representa a única possibilidade de sobrevivência ao idoso, sendo revestida de sofrimentos e limitações que interferem nas condições de vida, o presente estudo propõe-se a compreender a história de vida de um grupo de idosos institucionalizados. Tratase de estudo qualitativo realizado a partir das narrativas de oito idosos residentes em uma instituição de longa permanência (ILP). A interpretação dos dados teve como referência o método de análise de conteúdo modalidade temática. Os resultados apontam para semelhanças nas trajetórias marcadas pelo desfavorecimento do contexto sócio-histórico. Depreende-se que a atenção ao processo de envelhecimento deve se iniciar na infância, por meio de condições propícias ao crescimento e desenvolvimento nos aspectos biopsicossociais.

\section{Abstract}

Considering that institutionalization often represents the elderly's only possibility of survival, involving suffering and limitations that influence life conditions, this study aims to understand institutionalized elderly's life history. This is a qualitative research made from eight elderly's narratives, living in long-term facilities. Interpretation of data was based on the content analysis method thematic modality. The results present similarities in trajectories, marked by disfavoring of social historic content. It may be concluded that attention to the aging process starts in childhood, observing bio-psychosocial conditions of growing and development.

1 Curso de Enfermagem, Faculdade de Medicina de Marília. Marília, SP, Brasil.

2 Curso de Medicina, Faculdade de Medicina de Marília. Marília, SP, Brasil.

* Projeto de pesquisa aprovado pela FAPESP como bolsa de Iniciação Científica.

Correspondência / Correspondence

Maria José Sanches Marin

Av. Brigadeiro Eduardo Gomes, 1886 - Jd Itamaraty

17514-000 Marília, SP, Brasil

Email: marnadia@terra.com.br

Key words: Elderly. Institutionalization. Life Cycle Stages.
Palavras-chave: Idoso. Institucionalização. Fases do Ciclo da Vida. 


\section{INTRODUÇÃO}

Muitas são as circunstâncias que levam as pessoas a viver melhor ou pior as diferentes fases da vida. No entanto, a velhice parece ser aquela em que os enfrentamentos das adversidades impostas pelo cotidiano se tornam mais complexos. Os idosos são propensos a perdas e dependência no decorrer da vida, pois mesmo que tenham boa saúde, se debilitam paulatinamente.

A preocupação com a condição de vulnerabilidade em que se encontram os idosos vem aumentando nas últimas décadas, em decorrência do intenso processo de envelhecimento $d a$ população. Os desafios frente a essa realidade são maiores sobretudo nos países em desenvolvimento como o Brasil, que não dispõem de recursos sociais para o atendimento dessa parcela da população. Estima-se que, em 2025, entre os dez países do mundo com maior número de idosos, cinco serão países em desenvolvimento, incluindo o Brasil. ${ }^{1}$

O envelhecimento tende a ser delicado e doloroso para muitos idosos. Com frequência, eles se veem frente ao isolamento, à falta de apoio social, à dificuldade em lidar com o próprio processo de envelhecimento, com a morte do cônjuge, o abandono familiar, as dificuldades para se manter financeiramente, o que também pode desencadear doenças físicas e psíquicas. A própria transformação social dos últimos anos, incluindo os novos arranjos familiares, o grande número de separações, o avanço tecnológico e científico de domínio dos mais jovens e a inserção da mulher no trabalho fora do lar, são fatores que contribuem para a falta de apoio aos idosos.

Nesse contexto, merece destaque o envelhecimento com dependência, pois esses indivíduos demandam cuidados e responsabilidade que implicam disponibilidade de tempo de seus familiares, normalmente seus principais cuidadores. Cuidar do idoso em casa não é uma tarefa amena, principalmente considerando as dificuldades socioeconômicas em que vive a maior parcela da população brasileira. Assim, as instituições de longa permanência (ILP) passam a ser a opção viável.
Existem em torno de 19 mil idosos atendidos em ILPs, mas o número pode ser maior se levarmos em conta que muitas delas não estão cadastradas e funcionam na clandestinidade. ${ }^{2}$

Os motivos descritos para a internação nas ILPs incluem as dificuldades das famílias em acolhê-los por falta de espaço, recursos, uma estrutura familiar que respeite o idoso ou por incapacidade de cuidar deles devido a situações especiais como inserção dos membros no mercado de trabalho, abandono pela família, dificuldades de encontrar um cuidador, pobreza, viuvez e opção do próprio idoso por se achar um entrave para a família. ${ }^{3}$

Embora as ILP atendam os idosos quanto às necessidades de moradia, higiene, alimentação e acompanhamento médico, há o inconveniente de afastar o idoso de seu convívio familiar, favorecendo o isolamento e a inatividade física e mental, com consequências negativas à sua qualidade de vida. ${ }^{4}$

O idoso institucionalizado é geralmente uma pessoa desmotivada para a vida, sem expectativas e com esperanças de retorno ao ambiente familiar. Além disso, ele ainda se vê na condição de ter que conviver com pessoas muito diferentes, às vezes até não idosas, com doenças incapacitantes, mentais, psiquiátricas e com alcoolistas, o que torna o ambiente desconfortável. ${ }^{5}$

Para o idoso institucionalizado, as perdas são muitas, e isto justifica a grande incidência de estados depressivos, sentimentos de solidão e limitação das possibilidades de uma vida ativa. ${ }^{6}$ Relegado a uma espécie de isolamento e muitas vezes privado de suas atividades familiares e sociais, vive uma situação limitada e prejudicada, e mesmo que ele tenha monitoramento da sua saúde física, algo lhe falta, como a mobilidade social, vida afetiva e sexual, além de autonomia financeira. ${ }^{7}$

Por esses motivos, a institucionalização deve ser considerada como a última alternativa para amparo e cuidado do idoso. Tal aspecto é reafirmado pela Política Nacional do Idoso, que preconiza a assistência no domicílio com ênfase 
na promoção da saúde, na prevenção de incapacidades e na manutenção da capacidade funcional do idoso dependente. ${ }^{8}$

Frente aos fatores que afetam as condições de vida dos idosos institucionalizados, passam a interessar suas experiências ao longo da vida. Teriam eles, na atualidade, condições muito diferenciadas do ponto de vista social, afetivo e de construção de vínculos durante as demais fases da vida? A literatura, embora rica em estudos que abordam diferentes aspectos das condições de vida dos institucionalizados, ainda não fornece maiores esclarecimentos sobre o tema.

Diante da situação em que se encontram os idosos institucionalizados, propõe-se para o presente estudo compreender o percurso de suas vivências, considerando que tais dados podem subsidiar ações sociais e de saúde visando à melhoria das condições de vida dessa parcela da população.

\section{MÉTODO}

O estudo foi desenvolvido na modalidade qualitativa, pela possibilidade de maior aproximação com o objeto de pesquisa e compreensão das experiências no seu todo. ${ }^{9}$ Realizou-se em um lar para idosos, mantido por instituição religiosa de uma cidade do interior paulista, o qual conta atualmente com 60 idosos, sendo 25 do sexo masculino e 35 do sexo feminino. Desses idosos, aproximadamente $5 \%$ residem no lar por ordem judicial, $15 \%$ por conta própria e $80 \%$ por opção de familiares. Todos os idosos são aposentados, sendo que $70 \%$ de cada aposentadoria são destinado à administração desse lar e $30 \%$ ao próprio idoso. A instituição conta com 32 funcionários diários e, duas vezes por semana, com estudantes de fisioterapia de uma universidade particular da cidade. Outros recursos para o lar provêm dos governos federal, estadual e municipal, além de doações e ajuda de particulares.

O referencial metodológico refere-se à história oral ou método biográfico, em que o registro da história de vida de indivíduos, ao focalizar suas memórias pessoais, delineia também uma visão mais concreta da dinâmica de funcionamento e das várias etapas da trajetória do grupo social ao qual pertencem; ${ }^{10}$

Nos trabalhos com história oral, atenta-se para um novo olhar, uma nova postura acerca do estudo dos homens no tempo, em que o pesquisador se atém a novos focos e reexamina focos já estudados. ${ }^{11}$

A entrevista, fonte oral utilizada para o estudo e feita com os idosos, teve como eixo o relato dos fatos marcantes durante a vida deles. Selecionaramse, de forma aleatória, oito idosos, tendo como pré-requisito residir no lar há pelo menos um ano e ter a capacidade cognitiva preservada, o que foi avaliado por meio do Mini-Exame do Estado Mental (Mini-mental), sendo necessária uma pontuação maior ou igual a 17 para analfabetos e 24 para os alfabetizados. ${ }^{12}$

Os dados foram coletados e transcritos pelas próprias pesquisadoras, visando a facilitar a captação de detalhes, como pausas e entonações, para maior aproximação com o objeto de estudo. Pelas características dos entrevistados, foi necessário mais de um encontro para a realização da entrevista. Esse procedimento se fundamenta na perspectiva de que a entrevista representa a base do trabalho com história oral, sendo um momento de interação com fundamentos historiográficos, pois trata-se de um procedimento cuidadoso na constituição de fontes históricas. ${ }^{13}$

Para análise dos dados, optou-se pela análise de conteúdo, modalidade temática, indicada para estudos de opiniões, atitudes, valores e tendências. Inicialmente, realizou-se leitura de cada uma das entrevistas visando a organização do material e reconhecimento das ideias iniciais do texto. $\mathrm{Na}$ sequência, o material foi submetido a um estudo mais aprofundado, orientado pelo objetivo e referencial teórico, visando ao desmembramento das unidades de registro, ou seja, à codificação que corresponde à transformação dos dados brutos do texto. Essa transformação, por recorte 
do texto, classificação e agregação, possibilitou o alcance de uma representação do conteúdo para formulação das categorias. Posteriormente, foram estabelecidas relações e deduções subsidiadas pela reflexão e fundamentação teórica. ${ }^{9}, 14$ As falas que ilustram as categorias foram codificadas por dados como sexo (masculino ou feminino), idade e tempo de institucionalização.

O projeto contou com a anuência da diretora do lar e com a aprovação do Comitê de Ética e Pesquisa com Seres Humanos da Faculdade de Medicina de Marília, protocolo $n^{\circ}$ 139/10. Os idosos foram informados sobre a finalidade do estudo e assinaram o termo de consentimento livre e esclarecido; aqueles que não sabiam escrever colocaram a impressão digital.

\section{RESULTADOS E DISCUSSÃO}

Quanto às características sociodemográficas, quatro eram do sexo masculino e quatro do sexo feminino, com idade variando de 62 a 79 anos e tempo de institucionalização de um ano e seis meses a 11 anos.

A análise dos dados permitiu elaborar quatro categorias temáticas que retratam as diferentes fases do ciclo vital.

\section{Infância e adolescência marcadas por perdas, falta de cuidados e necessidade de inserção precoce no mercado de trabalho}

As narrativas seguintes mostram que essas pessoas conviveram com a perda e o sofrimento desde a infância, precisaram se inserir, precocemente e em condições precárias, no mercado de trabalho, tiveram vínculos afetivos rompidos e não tiveram oportunidade de acesso à escola e aos direitos de cuidado à saúde.

"Vida boa é quando tinha pai e mãe em casa. Tudo era uma vida boa. A gente tinha carinho. Ai, depois que morreram fiquei só andando pela casa dos outros, e nunca ficou que nem de primeiro [...] Trabalhei na lavoura de café, tocando roça, panhando algodão, batendo amendoim, comecei trabalha com 10 anos.
Com 10 anos, eu tava na roça, todo dia, por isso também não fui na escola. Fui crescendo e foipassando o tempo...” (M, 79 anos, nove anos na instituição).

"Até os 6 anos foi bacana. Com 6 anos me contaram que eu não era filha de quem en pensava que era minha mãe, ela era minha avó. A minha mãe era minha irmã, meus irmãos eram meus sobrinhos [...] Eu nunca chamei minha mãe de mãe, chamava minha avó de mãe. Chamei até ela morrer. Nunca morei com a minha mãe, nunca fui de ter amizade com ela" (F, 62 anos, dois anos na instituição).

"[...] eu sempre morei no sitio com (nome). Eles me criaram. Eu, eu sou irmã de criação... Eles que cuidô de mim. Eu trabalbei na roça desde criança [...] Nunca brinquei, só trabalhei. Eu trabalhava na roça, carregava água, enchia água. [...] en tava morrendo de dor de cabeça e estamo ruim e não me deram nenbum remédio, falaram que eu tinha preguiça por causa do serviço" (F, 73 anos, quatro anos na instituição).

Evidencia-se, nestas falas, o nítido sentimento de tristeza provocado pelas circunstâncias das perdas, que se refletem nas relações afetivas e sociais. Tais circunstâncias parecem ter impedido essas pessoas de viver e conviver plenamente no contexto familiar e, possivelmente, dificultado o pleno desenvolvimento biopsicossocial necessário para uma vida digna. Acrescenta-se que as vivências de abandono durante outrasfases podem levar esse sentimento atéa velhice. ${ }^{15}$

O respeito ao direito da criança às necessidades físicas, mentais e de desenvolvimento social contribui para o bem-estar do indivíduo na vida adulta. Destaca-se que a inserção precoce no mercado de trabalho leva à desqualificação para o trabalho e, como consequência, à baixa remuneração. ${ }^{16}$ Ademais, é na juventude que se afirma a identidade social e, considerando que toda identidade social é relacional, o contexto sociocultural no qual se insere a família do jovem influencia seu desenvolvimento, delineando possibilidades e limites, conforme estudos, mesmo antes da fecundação. Para o desenvolvimento saudável, é preciso definir as relações e processos de identidade, em espaços apropriados à autoestima, à criatividade e ao projeto de vida. ${ }^{17}$ 
Esses idosos, portanto, não tiveram um contexto apropriado ao desenvolvimento seguro e saudável. Acrescenta-se que, no Brasil, apenas com a Constituição Federal de 1988 e com o Estatuto da Criança e do Adolescente, criado em 1990, é que se tem o delineamento dos seus diretos. Então, quando esses indivíduos viveram a infância, as leis de proteção ainda não estavam claramente definidas. ${ }^{18}$ Os relatos revelaram que, desprovidos de qualquer proteção, restava-lhes serem aceitos em um núcleo familiar qualquer, oferecendo seus préstimos trabalhistas.

Vida adulta permeada pela precariedade nas condições de trabalho e fragilidade nos vínculos afetivos

Frente aos percalços da infância e adolescência, não é possível imaginar que a vida adulta tivesse uma trajetória muito diferenciada. Os idosos institucionalizados transformaram-se em adultos sem muitas perspectivas, tendo que enfrentar trabalhos subalternos, com baixa remuneração e sem direitos trabalhistas, o que lhes determina condições precárias de vida, assim como se observa nas falas que seguem:

[...] "que quando eu fui pra São Paulo, me encaixei na afundição, trabalhei de..., trabalhei um ano e... um mês de inspetor de peças, inspecionava peças, aí..., me mandaram embora, aí, não achava outra coisa boa, fui procurar barragem, trabalhei em duas, na... Três Lagoas e Mato Grosso, em duas barragens trabalhei, depois vim procurar firma de novo, ai não achava, aí.. fui obrigado a cair na lavoura" (M, 77anos, cinco anos na instituição).

Salienta-se que a atividade que eles conseguiram exercer pela falta de formação para o exercício de uma atividade mais qualificada é monótona, braçal, repetitiva, desinteressante e desestimulante. Desta forma, o aspecto prazeroso do trabalho torna-se pouco efetivo e, sobressaindo o sofrimento, tornou-se difícil para essas pessoas a manutenção no emprego.

É possível que as precárias condições de vida e as carências de convivência familiar, desde os primeiros anos de vida, tenham resultado em consequências negativas à aquisição de cultura, de inteligência verbal e equilíbrio emocional necessários à manutenção dos vínculos afetivos, ${ }^{19}$ pois se observa que este também foi um aspecto marcante em sua vida adulta.

"E eu nunca casei, fiquei só amigado uns tempo, num deu certo, e to aqui solteiro" (M, 79 anos, nove anos na instituição).

(Sobre o marido) "Largamos. Nós vivemos juntos mais de 30 anos. Todos os meus filhos, deixei todo mundo criado, en aguentava ele por causa dos filhos, ai não aguentei mais e larguei" (F, 62 anos, dois anos na instituição).

"Num era casado, mas juntamo os trapos. A gente viveu pouco tempo. Eu tinha uma que era mais velha e outra, mais nova. Assim, eu num tinha elas ao mesmo tempo, mas por etapas” (M, 75 anos, 11 anos na instituição).

Ao considerar o modo pelo qual foi possível para esses idosos construir seu espaço e manter a sobrevivência, é de se esperar eles não contem, neste momento, com uma estrutura parental capaz de apoiá-los, tanto no aspecto econômico como no afetivo.

\section{A institucionalização como a única possibilidade de sobrevivência na velhice}

Assim, a forma como viveram a infância, a adolescência e a vida adulta, fases marcadas pela pobreza, trabalho desqualificado e perda de vínculos, parece ter-se tornado um ciclo vicioso que os levou à velhice com perpetuação do sofrimento e solidão.

Ao abordarem a institucionalização, os idosos entrevistados atribuem o fato à falta de outro recurso, uma vez que, ao perderem a autonomia e a capacidade de tomada de decisões para administrar a vida, sem contarem com apoio familiar, restou-lhes como solução de sobrevivência a institucionalização.

"Eu que quis vim pra cá. Minha filha tava no Japão, não ligava mais pra mim" (F, 73 anos, quatro anos na instituição). 
"Eu tô me dando bem aqui, viu. Mas gostá, se te falarisso, eu tô mentindo..."(M, 75 anos, 11 anos na instituição).

"O momento mais marcante da minha vida foi ter vindo pra cá, porque aqui foi um bom lugar, apesar que en achava ruim pacas" (F, 62 anos, dois anos na instituição).

Dados estatísticos demonstram que, no Brasil, a família representa a principal fonte de apoio à pessoa idosa, sobretudo entre as camadas mais carentes da população, as quais se organizam em coabitação, incluindo pessoas de várias gerações de modo a se autoajudarem. ${ }^{20}$

Entre as histórias de alguns idosos se observa que, embora em outras fases tenham compartilhado espaço doméstico com familiares, na atualidade aquelas pessoas buscaram outras formas de levar a vida, independentemente do idoso, deixando-o no abandono e na solidão.

Outro aspecto que nos chama a atenção referese à resistência que eles apresentam para sair das suas casas. Trata-se, para eles, de uma situação nada confortável, mesmo frente à incapacidade de viver de forma independente. Estudo que avaliou os sentimentos de solidão experienciados por idosos intitucionalizados em relação aos nãoinstitucionalizados constatou que tais sentimentos estão mais presentes naqueles institucionalizados, levando-nos considerar que, ao conviverem com pessoas afetivamente, eles significativas apresentam melhores condições de suportar as adversidades do processo de envelhecimento. ${ }^{21}$

\section{0 sentimento de ser cuidado na instituição}

Conforme depoimentos, a perda da independência e, consequentemente, a necessidade de ser cuidado por outros, levaram os idosos a necessitar da ILP. Percebe-se isso nas falas seguintes.

"Mas aqui, porque en fiquei doente, cuidaram de mim, viram tudo que eu tinha; eu fiquei ruim pelas pingas que eu tomava há um ano e meio atrás" (F, 62 anos, dois anos na instituição).
"Eu me dou bem aqui porque sou bem tratado, num sou melhor que os outros, mas também num sô tratado pior do quase todos os outros" (M, 75 anos, 11 anos na instituição).

"Eu gosto de ficar aqui [...] Tomo remédio cedo, à noite e meio dia. Tomo remédio pra perna aqui..." (F,73 anos, quatro anos na instituição).

O cuidado com a saúde é importante nesta fase da vida, indubitavelmente. Muito embora a velhice não seja sinônimo de doença, é comum que se chegue a esta idade com alguma doença crônica não-transmissível ou algum grau de dependência, o que demanda cuidado diário, sobretudo para o uso de medicamentos e alimentação.

Em estudo sobre a percepção das condições de saúde entre idosos institucionalizados, constatou-se que eles a relacionam com a ausência de dor e desconforto físico e com a segurança proporcionada pela instituição que garante alimentação, moradia e atendimento médico. Por outro lado, as autoras concluem que o asilamento configura-se também como abandono, o que influencia diretamente o estado de saúde. ${ }^{22}$

Essas mesmas condições estão presentes entre os idosos, atores das histórias de vida aqui relatadas, pois verbalizam o sentimento de ser bem cuidado como uma forma de conformismo à situação, frente à inexistência de outra possibilidade de ser cuidado e, nas entrelinhas, evidencia-se o descontentamento com a situação vivenciada.

\section{CONSIDERAÇÕES FINAIS}

No presente estudo, ao analisar a história de vida de oito idosos que vivem em ILPIs, não se teve a pretensão de generalização dos dados, visto que, apesar de nesta fase as histórias se diferenciarem, alguns aspectos mostraram semelhanças. Destacam-se a baixa condição socioeconômica durante todo o curso da vida, a perda precoce do núcleo familiar, a baixa escolaridade, o trabalho infantil e afalta de construção de fortes vínculos afetivos. Revela-se também que foi o conjunto de experiências vivenciadas ao longo da 
vida que lhes permitiu construir uma trajetória particular, diferente em muitos aspectos do observado entre os idosos em geral.

Não se quer com isso afirmar que outros idosos, vivendo com familiares, estejam em melhores condições, pois são muitos os motivos que os levam a encerrar sua trajetória de vida sem um mínimo de dignidade e respeito, mesmo inseridos em seu lar. No entanto, os percalços de suas histórias de vida parecem ter contribuído para a atual situação de abandono e solidão na velhice.

\section{REFERÊNCIAS}

1. Instituto Brasileiro de Geografia e Estatística( IBGE). Estatística do século XX. Rio de Janeiro: IBGE; $2003.540 \mathrm{p}$.

2. Davim RMB, Torres GV, Dantas SMM, Lima VM. Estudo com idosos de instituições asilares no município de Natal/RN: características socioeconômicas e de saúde. Rev Latinoam Enferm 2004 maio/jun.; 12(3): 518-24.

3. Telles Filho PCP, Petrilli Filho JF. Causas da inserção de idosos em uma instituição asilar. Rev Enferm 2002 abr.; 6(1): 135-43.

4. Herédia VBM, et al. A realidade do idoso institucionalizado. Text Envelhec 2004 jul./dez.; 7(2): 9-31.

5. Lima MAXC. Retratos do asilo: o termo "institucionalização". Disponível em: URL: http://www.portaldoenvelhecimento.net/ acervo/retratos/retratos3.htm

6. Danilow MZ, et al. Perfil epidemiológico, sociodemográfico e psicossocial de idosos institucionalizados do Distrito Federal. Comum Cienc Saúde 2007 jan./mar.; 18(1): 9-16.

7. Tier CG. Depressão em idosos residentes em uma Instituição de Longa Permanência (ILP): identificação e ações de enfermagem e saúde. Rio Grande do Sul. Dissertação [Mestrado em Enfermagem]. -Fundação Universidade Federal do Rio Grande; 2006.

8. Brasil. Ministério da Saúde(Brasil). Portaria ${ }^{\circ}$ 1.395, de 10 de dezembro de 1999. Política Nacional de Saúde do Idoso. Brasília; 1999. Disponível em: URL: http:// dtr2004.saude.gov.br/susdeaz/legislacao/ arquivo/Portaria_1395_de_10_12_1999.pdf
Considerando que os aspectos destacados nas falas dos entrevistados ao resgatarem suas histórias de vida retratam trajetórias igualmente marcadas pelo desfavorecimento do contexto sóciohistórico, a atenção com o processo de envelhecimento deve se iniciar na infância, por meio de condições propícias ao crescimento e desenvolvimento dos indivíduos nos aspectos biopsicossocial, especialmente aqueles de classes sociais desfavorecidas, a fim de que tenham condições de manter o convívio familiar e os laços afetivos.

9. Minayo MCS. O desafio do conhecimento. São Paulo: Hucitec; 2003.

10. Meihy JCSB. Manual de história oral. 4. ed. São Paulo: Loyola; 2002. 248 p.

11. Spindola T, Santos RS. Trabalhando com a história de vida: percalços de uma pesquisadora. Rev Esc Enferm USP 2003 jun.; 37(2): 119-26.

12. Brucki SMD,et al. Sugestões para o uso do miniexame do estado mental no Brasil. Arq Neuropsiquiatr 2003 set.; 61(3B): 777-81.

13. Ludke M, André MEDA. Pesquisa em educação: abordagens qualitativas. São Paulo: EPU; 1986.99 p.

14. Bardin L. Análise de conteúdo. Lisboa: Edições 70; 2003. 226 p.

15. Heréida VBM, Cortelleti IA, Casara MB. Abandono na velhice. Text Envelhec 2005 set./ dez.; 8(3): 307-19.

16. Prebianchi HB. Medidas de qualidade de vida para crianças: aspectos conceituais e metodológicos. Psicol Teoria Pratica 2003 jan./ jun.; 5(1): 57-69.

17. Cruz Neto O, Moreira MR.Trabalho infantojuvenil: motivações, aspectos legais e repercussão social. Cad Saúde Pública 1998 abr./jun.; 14(2): 437-41.

18. Traverso-Yépes MA, Pinheiro VS. Adolescência, saúde e contexto social: esclarecendo práticas. Psicol Soc 2002 jul./dez.; 14(2): 133-47.

19. Bowlby J. Formação e rompimento dos laços afetivos. 3. ed. São Paulo: Martins Fontes; 2001. $228 \mathrm{p}$. 
20. Teixeira SM, Rodrigues VS. Modelos de família entre idosos: famílias restritas ou extensas? Rev Bras Geriatr Gerontol 2009 set./dez.; 12(2): 239-54.

21. Barroso VL. Órfãos geriatras: sentimentos de solidão e depressividade face ao envelhecimento: estudo comparativo entre idosos institucionalizados e não institucionalizados. Porto: Psicoglobal; 2008.

Disponível em: URL: http://

www.psicopatologia.com.pt/artigos/textos/ TL0091.pdf

22. Pestana LC, Espirito Santo FH. As engrenagens da saúde na terceira idade: um estudo com idosos asilados. Rev Esc Enferm USP 2008 jun.; 42(2):268-75.

Recebido: 22/3/2011

Revisado: 08/7/2011

Aprovado: 20/9/2011 